\title{
Microzooplankton grazing dynamics: parameterizing grazing models with dilution experiment data from the California Current Ecosystem
}

\author{
Qian P. Li*, Peter J. S. Franks, Michael R. Landry \\ Integrative Oceanography Division, Scripps Institution of Oceanography, University of California, San Diego, \\ California 92195, USA
}

\begin{abstract}
Coupled physical-biological models are essential tools for enhancing our understanding of the potential effects of long-term climate change on planktonic ecosystems in the world's ocean. A major impediment to utilizing such models is obtaining accurate parameterizations of the modeled rate processes, such as growth and grazing. The California Current Ecosystem Long-Term Ecological Research (CCE-LTER) program has generated detailed data of phytoplankton growth and zooplankton grazing rates obtained in the field by the dilution technique. Here, we examine how data from dilution experiments can be used with nonlinear grazing models to study the dynamics of microzooplankton grazing. We use data from experiments conducted in 2007 to parameterize 3 different grazing functions and then test them against a more extensive data set from a CCE-LTER process cruise in 2006. We found that system-level parameterizations of the functional response relationships, representing the aggregate behaviors of predators and prey adapted to different environmental conditions, reasonably predict the shapes and magnitudes of vertical profiles of microzooplankton grazing in both coastal and open-ocean environments in the CCE. Predicting the magnitude of grazing rates - as opposed to just the concentrations of grazers - presents a much greater challenge for models in previous studies. Model-data comparisons are often difficult due to the lack of extensive data from different environments. Our study is a significant advance in the parameterization of zooplankton grazing models in the field and will serve as a solid base on which to pursue further studies of the planktonic ecosystems of the northeastern Pacific.
\end{abstract}

KEY WORDS: Grazing rates · Microzooplankton · California Current Ecosystem • Dilution experiments

Resale or republication not permitted without written consent of the publisher

\section{INTRODUCTION}

A large proportion of phytoplankton primary production in marine ecosystems is lost to the grazing of microzooplankton (Jackson 1980, Frost 1991, Strom et al. 2001), principally single-celled heterotrophic organisms such as ciliates, flagellates and dinoflagellates. This diverse assemblage of small grazers plays a crucial role in the regeneration of nutrients in the ocean (Calbet \& Landry 2004) and as links in the transfer of primary production from the smallest phytoplankton to larger heterotrophs in the food web. Understanding the role of microzooplankton in the planktonic food web requires quantification of their grazing rates relative to the growth rates of their phytoplanktonic prey. Commonly, this is done by conducting dilution experiments (Landry \& Hassett 1982, Landry et al. 1995, 2009), which separate the measured net rates of change of the phytoplankton community into intrinsic rate components of phytoplankton growth and grazing mortality from microzooplankton. 
In the past several decades, great progress has been made in planktonic ecosystem modeling; increasingly complex models include microzooplankton grazing more frequently. The results of ecosystem and biogeochemical models are very sensitive to the choice of grazing parameters as grazing exerts strong control on the balance of elements and the flow of energy within a system. The grazing of the zooplankton community on phytoplankton is generally represented as a nonlinear functional response, using either a 'predator-dependent' or a 'prey-dependent' relationship (e.g. Holling 1959, Ivlev 1961). The choice of grazing formula can profoundly influence model stability, equilibrium and trophic transfers (e.g. Franks et al. 1986, Steele \& Henderson 1992). Parameterization and testing of such formulations with field data requires adequate measurements not only of planktonic biomass and community structure, but also of grazing rates. Unfortunately, few field data sets are available that have sufficient abundance and detail to parameterize these grazing equations accurately. Because of the scarcity of field rate measurements, modelers often choose their parameters based on a few field or laboratory experiments or somewhat arbitrarily choose values that give the best model fits to other measured variables. These challenges in grazing model parameterization and testing have limited the soundness of planktonic ecosystem models and cast doubts on the results that they have generated.

Here, we parameterize and test 3 commonly used grazing functions with a large field data set of microzooplankton grazing rates acquired from process cruises of the California Current Ecosystem Long-
Term Ecological Research (CCE-LTER) program. The rate measurements come from dilution incubations conducted over the full depth range of the euphotic zone under varying environmental conditions from coastal upwelling to oligotrophic open ocean (Landry et al. 2009). The process studies were Lagrangian designed to reduce uncertainties associated with horizontal physical processes and to allow direct comparisons of experimentally determined rates with the observed net rates of phytoplankton change in the ambient environment. As a consequence, the rate data are uniquely field validated for model development, having been demonstrated to predict the mean direction and magnitude of chlorophyll change in the euphotic zone with $\mathrm{R}^{2}>0.9$ (Landry et al. 2009). In the present study, we use data from the experiments conducted in 2007 to parameterize grazing functions and then test predictions against a more extensive, independent data set from 2006.

\section{MATERIALS AND METHODS}

\section{Site description and Lagrangian experiments}

The CCE is located in the coastal upwelling region of the west coast of the USA and is one of the world's most productive marine ecosystems. In 2006 and 2007, 8 Lagrangian process studies were carried out during 2 cruises in the Southern California Current System (SCCS) (Fig. 1). The study area was roughly along the time-series sampling line 80 of the California Cooperative Oceanic Fisheries Investigations

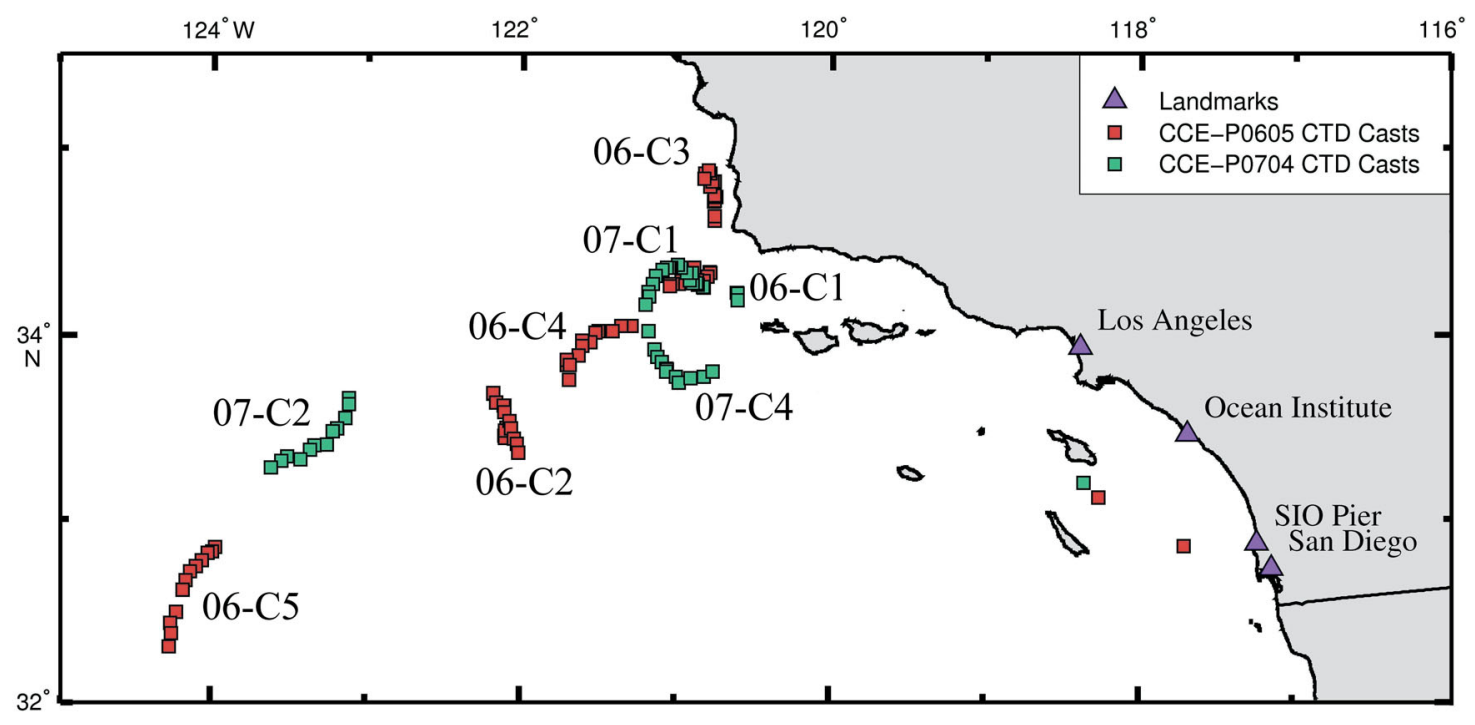

Fig. 1. Geographic locations of process studies in the California Current Ecosystem (CCE) region for CTD samples taken during 2 cruises; May 2006 (; P0605) and April 2007 (; P0704). 06(07)-C: Cycle no. in 2006 (2007) 
(CalCOFI) Program, which extends $>400 \mathrm{~km}$ seaward off of Point Conception, California. Each process study was called a 'cycle', in reference to the cycle of sampling and experimental activities conducted adjacent to a satellite-tracked drifter as it was followed over the course of 3 to $5 \mathrm{~d}$. Five experimental cycles were completed on a cruise of the RV 'Knorr' during May 2006, and 3 additional water parcels were studied on the RV 'Thomas G. Thompson' cruise during April 2007 (Landry et al. 2009). For each cycle, water parcels for experimental study, representing broad areas of relative near-surface homogeneity, were selected based on MODIS and SeaWiFS satellite observations and surveyed with a Moving Vessel Profiler (MVP, Brooke Ocean Technology). Experimental parcels were then marked with a mixed-layer drogued drifter, which both served as the moving point of reference for sampling and a platform for conducting experimental incubations under in situ conditions of light and temperature. Routine daily measurements at the drifter included depth profiles of temperature, salinity, nutrients, oxygen, chlorophyll $a$, phytoplankton community composition, zooplankton biomass, and rates of phytoplankton growth, grazing, primary production and particle export (Landry et al. 2009, Li et al. 2010).

\section{Measurement of phytoplankton and microzooplankton biomasses}

The seawater samples taken daily near the drift array were analyzed for microbial community abundance and biomass. They were also used to initiate daily dilution experiments that were incubated in situ below the drifter (Landry et al. 2009). For each sample, community analyses were based on the combination of flow cytometry (FCM) and epifluorescence microscopy (EPI) techniques. FCM analyses were used to distinguish population abundances of heterotrophic bacteria, photosynthetic bacteria and photosynthetic picoeukaryotes. Epifluorescence and inverted microscopy techniques were used to assess abundances, sizes and biovolumes of auto- and heterotrophic protists with cell sizes $>2 \mu \mathrm{m}$. FCM samples $(2 \mathrm{ml})$ were preserved with paraformaldehyde ( $0.5 \%$ final concentration), flash frozen in liquid nitrogen and stored at $-80^{\circ} \mathrm{C}$. Samples were thawed and analyzed using a Beckman-Coulter EPICS Altra flow cytometer with dual argon ion lasers (1 W at $488 \mathrm{~nm} ; 200 \mathrm{~mW}$ in UV) and a syringe pump for delivery of volumetric samples. Carbon biomasses of Prochlorococcus and Synechococcus were estimated from abundances, using conversion factors of 32 and $100 \mathrm{fg} \mathrm{C} \mathrm{cell}^{-1}$, respectively (Garrison et al. 2000).

For EPI analyses, protists, including diatoms and other eukaryotic phytoplankton as well as non-pigmented single-cell heterotrophs (grazers), were enumerated by protocols optimized for different size classes and groups. Small cells $(<10 \mu \mathrm{m})$ were enumerated in $50 \mathrm{ml}$ aliquots and analyzed on slides preserved with paraformaldehyde $(0.5 \%$ final concentration) and filtered onto $0.8 \mu \mathrm{m}$ black Nuclepore filters, both of which were stained with proflavin $(0.33 \% \mathrm{w} / \mathrm{v})$ and the DNA-specific fluorochrome DAPI $\left(10 \mu \mathrm{g} \mathrm{ml}^{-1}\right)$. Larger cells $(>10 \mu \mathrm{m})$ were also analyzed by EPI on 300 to $500 \mathrm{ml}$ subsamples preserved according to the sequential alkaline Lugolsodium thiosulfate-formalin protocol of Sherr \& Sherr (1993), stained with proflavin and DAPI, and mounted onto $8 \mu \mathrm{m}$ black Nuclepore filters. EPI slides were imaged and digitized at $630 \times(50 \mathrm{ml})$ or $200 \times(500 \mathrm{ml})$ using a Zeiss AxioVert 200M inverted microscope with an AxioCam HR color CCD digital camera. Counting and sizing were done with ImagePro image analysis software. For each imaged cell, biovolume $\left(\mathrm{BV}_{i} \mu \mathrm{m}^{3}\right)$ was calculated from length $(\mathrm{L}$, $\mu \mathrm{m})$ and width $(\mathrm{W}, \mu \mathrm{m})$ measurements using the approximation of a prolate sphere $\left(\mathrm{BV}=0.524 \mathrm{LW}^{2}\right)$. Cellular carbon estimates $\left(\mathrm{C}_{i}\right.$ pg C cell $\left.{ }^{-1}\right)$ were calculated from biovolumes based on the equations of Eppley et al. (1970): $\log _{10} \mathrm{C}=0.76\left(\log _{10} \mathrm{BV}\right)-0.352$ for diatoms and $\log _{10} \mathrm{C}=0.94\left(\log _{10} \mathrm{BV}\right)-0.60$ for nondiatom autotrophic and heterotrophic protists.

\section{Phytoplankton growth rate and grazing mortality}

Rate estimates of phytoplankton community growth and mortality due to microzooplankton grazing were assessed from chlorophyll a ( $\mathrm{chl}$ a) based analyses of in situ dilution incubations using the 2-treatment approach (Landry et al. 2009, 2011). For daily experiments, water collections were made at 8 depths chosen to be compatible with fixed attachment positions on the incubation line to capture the main features in downward chlorophyll fluorescence profiles and to extend from the near-surface ( 2 to $5 \mathrm{~m}$ ) to the base of the euphotic zone (deepest depth averaged $\sim 0.4 \%$ incident light). With water from each depth, prepared pairs of clear polycarbonate bottles $(2.7 \mathrm{l})$ were filled with whole seawater $(100 \%)$ and diluted seawater $(33 \%$, diluted with $0.1 \mu \mathrm{m}$ filtered seawater). The $33 \%$ treatment level was selected to produce a measurable dilution effect on net growth rate, while providing sufficient sample for supporting 
HPLC and microscopical analyses and sufficent prey to minimize negative nutritional impacts on micrograzers (e.g. Dolan et al. 2000). Seawater was filtered directly from the Niskin bottles using a peristaltic pump, silicone tubing and an in-line Suporcap filter capsule that had previously been acid washed $(10 \%$ trace-metal grade $\mathrm{HCl}$ followed by Milli-Q and seawater rinses). Dilution treatment bottles received pre-measured volumes of filtered water from the collection depths and then were gently filled (silicone tubing below the water level) with unscreened water from the Niskin bottles. The bottles were then tightly capped, placed into net bags and clipped onto attached rings at the depth of collection on the wire tether line hanging below the drifter. All experiments were started with water collected at the same time of day (02:00 h local time) with recovery and redeployments typically completed by $\sim 04: 30 \mathrm{~h}$ (presunrise). When experiments were done on successive days, the new experiment was first set up on deck. The drifter was then recovered, the net bags switched and the drifter redeployed, the total exchange taking about $15 \mathrm{~min}$. Rate assessments are for the total phytoplankton community, based on fluoromentric analyses of initial and final samples $(250 \mathrm{ml})$ for chl $a$. The samples were immediately filtered onto GF/F filters, and the chl a extracted with $90 \%$ acetone in a dark refrigerator for $24 \mathrm{~h}$. Extracted samples were shaken, centrifuged and quantified on a Turner Designs model 10 fluorometer.

To calculate the phytoplankton growth rate $\mu_{\mathrm{e}}$ and grazing rate $m_{\mathrm{e}}$ from the dilution experiment we follow Landry \& Hassett's (1982) equation for the rate of change of chlorophyll $\mathrm{Chl}$ in an incubation vessel:

$$
\frac{\mathrm{d} C h l}{\mathrm{~d} t}=C h l\left(\mu_{\mathrm{e}}-D m_{\mathrm{e}}\right)
$$

where e denotes the rates derived from the experimental manipulations and $D$ is the fraction of undiluted seawater in the incubation vessel. From Eq. (1) in the undiluted seawater treatment, we can calculate the net growth rate $k$ from the initial $C h l_{0}$ and final $\mathrm{Chl}$ chlorophyll concentrations and the incubation time $\Delta t$ :

$$
k=\frac{1}{\Delta t} \ln \left(\frac{C h l_{t}}{C h l_{0}}\right)=\mu_{\mathrm{e}}-m_{\mathrm{e}}
$$

Similarly, assuming a linear dilution of the grazing rate $m$ by a factor of $D$ in the diluted seawater treatment, the net phytoplankton growth rate $k_{\mathrm{d}}$ in the diluted treatment can be calculated from the initial diluted $\mathrm{Chl}$ concentration $\mathrm{Chl}_{0}^{\mathrm{d}}$ and the final diluted concentration $\mathrm{Chl}_{t}^{\mathrm{d}}$ :

$$
k_{\mathrm{d}}=\frac{1}{\Delta t} \ln \frac{C h l_{t}^{\mathrm{d}}}{C h l_{0}^{\mathrm{d}}}=\mu_{\mathrm{e}}-m_{\mathrm{e}} D
$$

Solving Eqs. (2) \& (3), the grazing $\left(m_{\mathrm{e}}\right)$ and growth $\left(\mu_{\mathrm{e}}\right)$ rates of phytoplankton can now be estimated from:

$$
m_{\mathrm{e}}=\frac{k_{\mathrm{d}}-k}{1-D}
$$

and

$$
\mu_{\mathrm{e}}=\frac{k_{\mathrm{d}}-k D}{1-D}
$$

The 2-point dilution method assumes linearity in the response of measured net growth rate $k_{\mathrm{d}}$ to dilution factor (Landry \& Hassett 1982). We tested this assumption during each of the coastal station cycles on the 2006 cruise (06-C1, -C3 and -C4 in Fig. 1) using mixed-layer water samples (from 5 to $12 \mathrm{~m}$ ) prepared as standard, multi-treatment dilution experiments (Landry et al. 2011) and incubated shipboard in surface seawater cooled incubators at $31 \%$ incident light for $24 \mathrm{~h}$. One experiment (06-C1, Fig. 2), conducted with the highest chl a concentration measured on the CCE cruises $\left(6 \mu \mathrm{g} \mathrm{l}^{-1}\right)$, shows a leveling of $k_{\mathrm{d}}$ at higher $D$ that could be indicative of grazing saturation. However, the 06-C3 experiment with comparably high chlorophyll (and the highest measured level of phytoplankton carbon biomass) shows no evidence of systematic nonlinearity. Strong linearity is evident at more typical phytoplankton concentrations observed in the CCE (06-C4, $1 \mu \mathrm{g}$ chl a $\mathrm{l}^{-1}$; Fig. 2). Standard dilution experiments also revealed that the upwelling-influenced stations shoreward of 06-C4 exhibited no response of added nutrients ( $4 \mu \mathrm{M}$ nitrate and $0.25 \mu \mathrm{M}$ phosphate) relative to no-nutrient controls. While offshore stations (not shown) did demonstrate a significant chlorophyll growth rate enhancement with added nutrients $\left(1.1 \mathrm{~d}^{-1}\right)$, the control-corrected growth and grazing rates estimates were comparable to rates $(0.3$ to $0.5 \mathrm{~d}^{-1}$ ) determined by the 2-treatment experiments incubated in situ without added nutrients.

\section{RESULTS AND DISCUSSION}

Our goal is to obtain estimates of microzooplankton grazing rates for the parameterization of planktonic ecosystem models. We proceed by assuming that there exists a functional response of the microzooplankton community to changes in phytoplankton concentration across the CCE region. Each $m$ derived from a dilution experiment represents a single, independently derived data point on this 

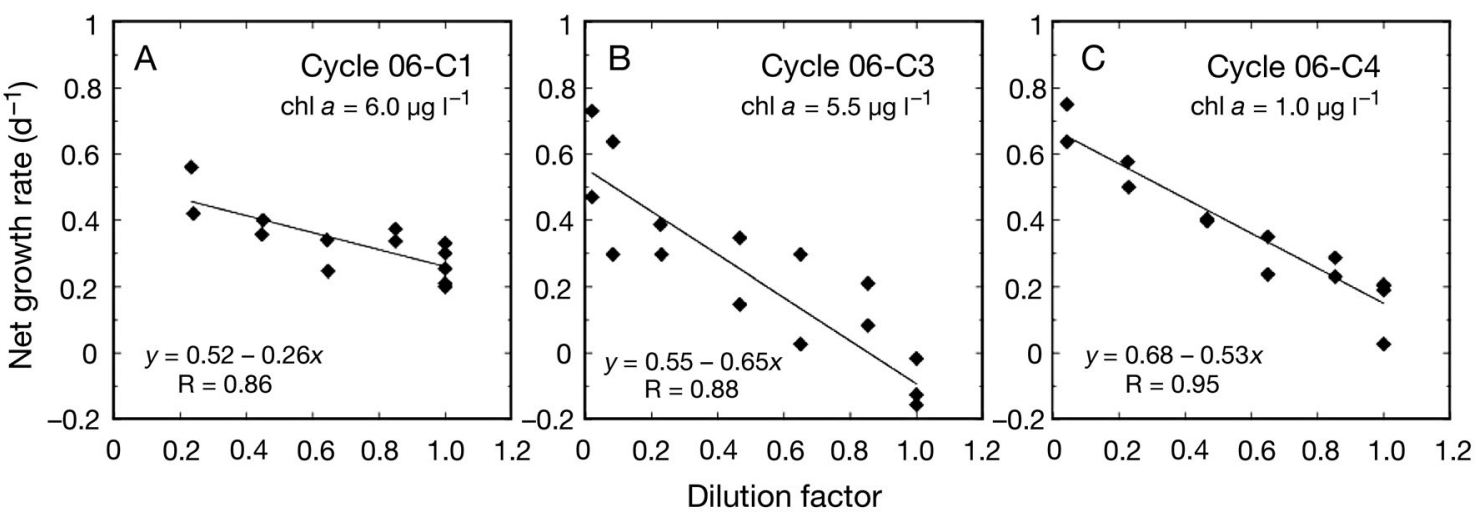

Fig. 2. Results of standard multi-treatment dilution experiments to test the linearity assumption conducted with mixed-layer seawater during Cycles (A) C1, (B) C3 and (C) C4 in 2006. Regression equations give chlorophyll-based estimates of phytoplankton growth and microzooplankton grazing rates $\left(\mathrm{d}^{-1}\right)$ as the $y$-intercepts and slopes, respectively

functional response curve, with a unique phytoplankton and microzooplankton biomass and grazing rate. For each of 3 alternative functional response relationships (Ivlev, Holling II and Holling III; see section below), we derive parameter values (and their errors) from best fits of the functional response to the data.

\section{Models of microzooplankton grazing functional response}

The Landry \& Hassett (1982) formulation for recovering estimates of $\mu$ and $m$ from the dilution manipulation is a simplified form of a more general equation for phytoplankton grazing mortality that involves a function (functional response) $f(P)$ describing how the grazing of microzooplankton $Z$ varies with concentration of phytoplankton $P$ :

$$
\frac{\mathrm{d} P}{\mathrm{~d} t}=\mu P-g_{\max } f(P) Z
$$

Here $g_{\max }$ is the maximum grazing rate of microzooplankton and $f(P)$ represents a system-level grazing response to phytoplankton prey. This systemlevel grazing function $f(P)$ is understood to represent the aggregate behavior of different assemblages of grazers and prey that arise under different environmental conditions of the SCCS, ranging from eutrophic coastal upwelling to oligotrophic offshore waters.

Equating the right-hand sides of Eqs. (1) \& (6), we obtain (for undiluted seawater):

$$
m P=g_{\max } f(P) Z
$$

From Eq. (7), the grazing rate $m$ thus can be written as:

$$
m=g_{\max } \frac{f(P)}{P} Z
$$

In Eqs. (7) \& (8), we assume that the grazing mortality rate $m$ is equal to $m_{\mathrm{e}}$ from the dilution experiments and is solely determined by the initial concentrations of $P$ and $Z$.

Rearranging Eq. (8), we have:

$$
\frac{m}{Z}=g_{\max } \frac{f(P)}{P}
$$

If the grazing function is linear (Holling I), the value of $f(P) / P$ would be a constant. Since $g_{\max }$ is a constant, the left side of Eq. (9) $(\mathrm{m} / Z)$ must be equal to a constant. This is clearly rejected by our field data from the SCCS (Fig. 3), which show that the measured $m_{\mathrm{e}} / Z$ varies from $<1 \mathrm{~d}^{-1} \mu \mathrm{M}^{-1}$ at high $P$ to $>12 \mathrm{~d}^{-1} \mu \mathrm{M}^{-1}$ at low $P$ concentrations. From this we conclude that the grazing function $f(P)$ must be nonlinear.

There are 3 common nonlinear formulations of $f(P)$ that we will examine:

$$
\begin{array}{ll}
f(P)=\left(1-\mathrm{e}^{-P / C_{\mathrm{I}}}\right) & \text { (Ivlev) } \\
f(P)=\frac{P}{C_{\mathrm{II}}+P} & \text { (Holling II) } \\
f(P)=\frac{P^{2}}{C_{\mathrm{III}}+P^{2}} & \text { (Holling III) }
\end{array}
$$

where $C_{\mathrm{I}}, C_{\mathrm{II}}$, and $C_{\mathrm{III}}$ are constants specifying the rate of increase of grazing with phytoplankton concentration. $C_{\mathrm{II}}$ and $C_{\mathrm{III}}$ are also called the half-saturation constants. The initial slopes of the Ivlev and Holling II functions are $C_{\mathrm{I}}^{-1}$ and $C_{\mathrm{II}}{ }^{-1}$, respectively. The units for $C_{\mathrm{I}}, C_{\mathrm{II}}$, and $C_{\mathrm{III}}$ are $\mu \mathrm{M}, \mu \mathrm{M}$ and $\mu \mathrm{M}^{2}$, respectively, determined from their relationship with $P$ in Eqs. $(10,11$ \& 12).

We now formulate the grazing mortality in terms of these 3 functional forms to facilitate parameterization using our data. For the Ivlev function, substituting 


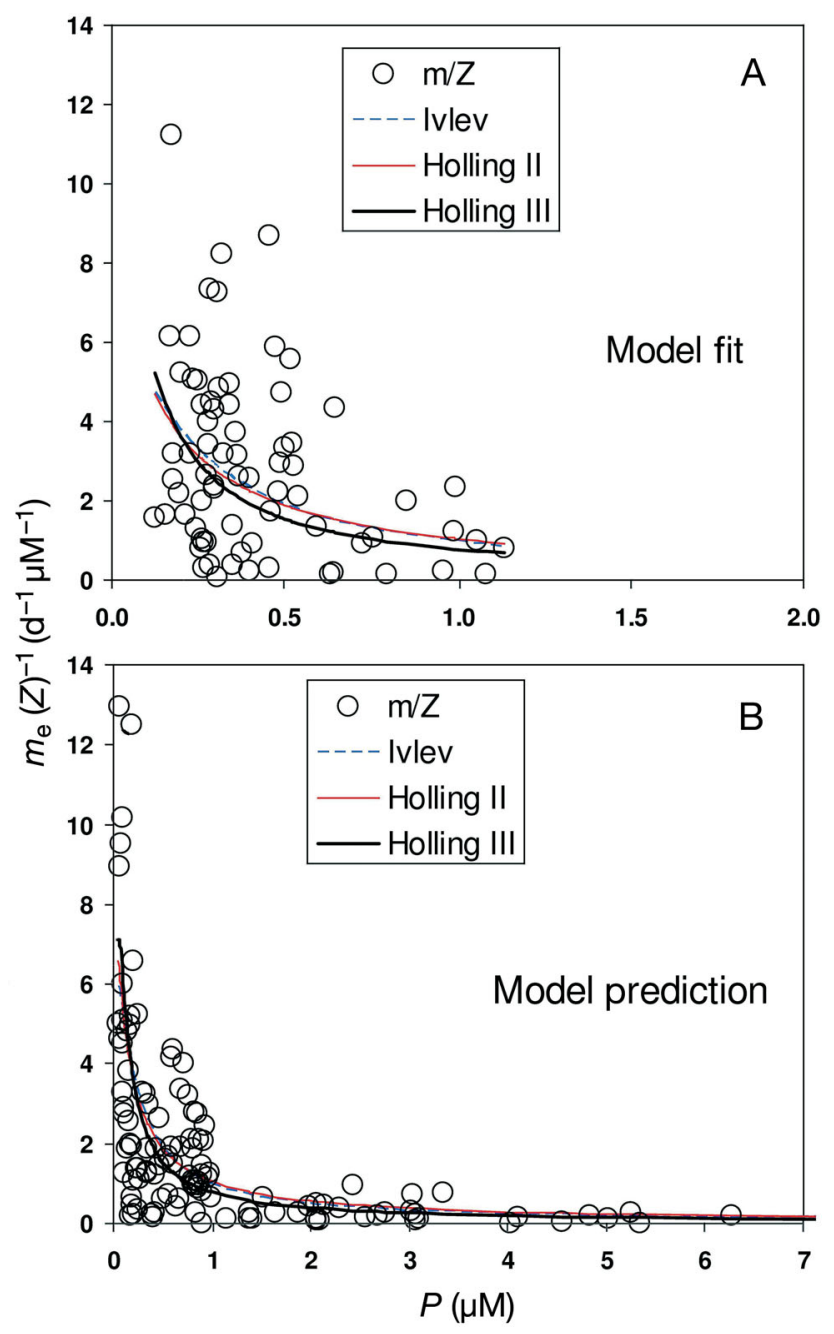

Fig. 3. (A) Best fits of the Holling II, Holling III and Ivlev functions to the 2007 California Current Ecosystem (CCE) data on microzooplankton grazing. (B) Predictions of the 3 models compared to the 2006 CCE data. m: grazing rate; $m_{\mathrm{e}}$ : phytoplankton grazing rate measured from dilution experiments; $Z$ : nitrogen biomass of microzooplankton; $P$ : nitrogen biomass of phytoplankton

Table 1. Mean $( \pm \mathrm{SD})$ parameters for the nonlinear grazing models $(n=72$ ). See 'Models of microzooplankton grazing functional response' for details. $g_{\text {max }}$ : maximum grazing rate of microzooplankton; $C$ : constants specifying the rate of increase of grazing with phytoplankton concentration

\begin{tabular}{|lcccc|}
\hline Model type & $g_{\max }\left(\mathrm{d}^{-1}\right)$ & $C(\mu \mathrm{M})$ & $\mathrm{R}^{2}$ & $\mathrm{p}$ \\
\hline Ivlev & $0.98 \pm 0.23$ & $0.136 \pm 0.143$ & 0.40 & $<0.0001$ \\
Holling II & $1.18 \pm 0.36$ & $0.126 \pm 0.084$ & 0.45 & $<0.0001$ \\
Holling III & $0.78 \pm 0.13$ & $0.003 \pm 0.002^{\mathrm{a}}$ & 0.46 & $<0.0001$ \\
& & & & \\
aUnits: $\mu \mathrm{M}^{2}$ & & & & \\
\hline
\end{tabular}

Eq. (10) into Eq. (9) yields:

$$
\frac{m_{\mathrm{e}}}{Z}=g_{\max } \frac{1}{P}\left(1-\mathrm{e}^{-P / C_{\mathrm{I}}}\right)
$$

For the Holling II form, substituting Eq. (11) into Eq. (9), we have:

$$
\frac{m_{\mathrm{e}}}{Z}=g_{\max } \frac{1}{C_{\mathrm{II}}+P}
$$

Finally, for the Holling III functional form, substituting Eq. (12) into Eq. (9) gives:

$$
\frac{m_{\mathrm{e}}}{Z}=g_{\max } \frac{P}{C_{\mathrm{III}}+P^{2}}
$$

\section{Parameterization of grazing models}

For each grazing function (Eqs. 10, 11 \& 12), the parameters in $f(P)$ were estimated by fitting the field measurements of $m_{\mathrm{e}} / Z$ and $P$ to Eqs. $(13,14 \& 15)$. We used Matlab routine 'fminsearch' to find the parameter values that minimized the sum of the squared residuals of the modeled and observed grazing rates. We used data from the 2007 CCE cruise (P0704) to parameterize the grazing models and the larger data set from the 2006 CCE cruise (P0605) to test the model parameterizations (Fig. 3). $P$ and $Z$ were expressed as nitrogen biomass $\left(\mu \mathrm{mol} \mathrm{N}{ }^{-1}\right)$, converting from carbon biomass with assumption of a Redfield ratio for $\mathrm{N}$ : C.

The results of the model parameterization using the 2007 field data are shown in Table 1. These parameterizations indicate that the maximum grazing rate of microzooplankton $g_{\max }$ estimated for the Holling II model is slightly higher than that of the Ivlev model. Both, however, are higher than the $g_{\max }$ estimated from the Holling III model. For the Holling II function, our estimates from the SCCS are close to those used previously in ecosystem simulations of the equatorial Pacific upwelling region (Chai et al. 2002: $g_{\max }=1.35 \mathrm{~d}^{-1}$ and $\left.C_{\mathrm{II}}=0.5 \mu \mathrm{M}\right)$. However, they are much larger than those used in some other studies (e.g. Follows et al. 2007: $g_{\max }=0.2 \mathrm{~d}^{-1}$ and $C_{\mathrm{II}}=$ $0.1 \mu \mathrm{M})$. For the Ivlev function, the estimates of $0.98 \mathrm{~d}^{-1}$ for the maximum grazing rate and $0.136 \mu \mathrm{M}$ for the Ivlev constant are lower than those used in the ecosystem model of Franks et al. (1986) $\left(g_{\max }=0.16\right.$ to $1.5 \mathrm{~d}^{-1}$ and $C_{\mathrm{I}}=0.5$ to $10 \mu \mathrm{M}$ ). For the Holling III function, our estimated values of maximum grazing rate and half saturation constant are lower than those used by Fennel et al. $\left(2001 ; g_{\max }=2.0 \mathrm{~d}^{-1}\right.$ and $C_{\mathrm{III}}=$ $0.5 \mu \mathrm{M}^{2}$ ) and Edwards (2001; $g_{\max }=0.6$ to $1.4 \mathrm{~d}^{-1}$ and $C_{\text {III }}=0.06$ to $1.56 \mu \mathrm{M}^{2}$ ), which also included contributions of meso- and macro-zooplankton to total grazing of the phytoplankton community. 
Grazing rates estimated in feeding experiments with individual herbivores are often expressed as ingestion (biomass consumed ind.$^{-1} \mathrm{~d}^{-1}$ ) or clearance rates (volume cleared ind..$^{-1} \mathrm{~d}^{-1}$ ) (Hansen et al. 1997). To compare clearance rates to grazing rates acquired from dilution experiments, we need to convert the clearance rate to specific grazing rates $m\left(\mathrm{~d}^{-1}\right)$. The specific grazing rate of microzooplankton can be estimated as the product of clearance rate $\left(\mu \mathrm{l}\right.$ ind..$\left.^{-1} \mathrm{~d}^{-1}\right)$ and grazer concentration (ind. $\mu \mathrm{l}^{-1}$ ). Our estimates of $g_{\text {max }}$ and $C_{\text {II }}$ using the Holling II grazing formula from the dilution experiments are near or within the range of values obtained for individual microzooplankton species based on laboratory feeding experiments (see the review of Hansen et al. 1997: $g_{\max }=2.4$ to $11.5 \mathrm{~d}^{-1}$ and $C_{\mathrm{II}}=0.06$ to $2.46 \mu \mathrm{M}$ for ciliates; $g_{\max }=$ 0.26 to $4.08 \mathrm{~d}^{-1}$ and $C_{\mathrm{II}}=0.2$ to $11 \mu \mathrm{M}$ for heterotrophic dinoflagellates; here, the half saturation constants are converted to $\mu \mathrm{M}$ nitrogen equivalents using a Redfield C:N ratio of 6.625).

From the functional response relationships fit to the 2007 data, we use independent data from the 2006 CCE process cruise to evaluate the model parameterizations. The predictions of $m_{\mathrm{e}} / Z$ from $P$ using the 2007 parameterized models show good agreement with the 2006 field rate estimates (Fig. 3B). Generally, $m_{\mathrm{e}} / Z$ is low in coastal areas, where the grazer biomass $(Z)$ is high. High values of $m_{e} / Z$ are mostly observed for the offshore oligotrophic regions, where they vary from 0 to $14 \mathrm{~d}^{-1} \mu \mathrm{M}^{-1}$. As we can also see from Fig. 3B, the absolute differences of $m_{\mathrm{e}} / Z$ estimates among the 3 nonlinear functions are smallest when the phytoplankton biomass is highest. At high phytoplankton concentrations, the nonlinear grazing functions should be close to saturation at the maximal grazing rate $g_{\text {max }}$.

The parameterizations for the 3 functional response relationships show that the standard deviation of $g_{\max }$ for the Holling II function is slightly higher than those for the Ivlev or Holling III functions (Table 1). The standard deviation for $C_{\mathrm{I}}$ in the Ivlev model is an order of magnitude or more larger than those of $C_{\mathrm{II}}$ and $C_{\mathrm{III}}$ for the Holling II and III models; part of this is accounted for by the fact that $C_{\text {III }}$ has different units. Significance tests for model fitting suggest that all of the 3 models fit the data equally well with $\mathrm{R}^{2}>0.36$ and $\mathrm{p}<0.0001$.

Several potential sources of error in our modeldata fitting are difficult to resolve. For example, not all potential prey $(P)$ are equally accessible to all consumers $(Z)$, and at least some pigmented cells such as mixotrophic flagellates and dinoflagellates are cryptic components of the grazer assemblage that we do include in our estimates of grazer biomass. In addition, our standard EPI slide preparations likely underestimate ciliated protozoa compared to invertedmicroscope analysis of acid Lugol-preserved samples (Taylor et al. 2011), and we did not include small juvenile stages of metazoan zooplankton among potentially important contributors to microzooplankton grazer biomass in nearshore waters. As a general practical concern, therefore, the efficiency with which we quantify abundance and biomass of different grazer groups can vary substantially across the large trophic gradient in our study area. The derived parameterizations relating rates to standing stocks thus incorporate many methodological issues and might be improved with a more detailed analysis of water parcel differences in composition of the micrograzer assemblages.

Temperature differences also have the potential to impact grazing rates (e.g. Eppley et al. 1970, Hansen et al. 1997). However, temperature variability in the euphotic zone was relatively modest during our springtime field studies, ranging from 10 to $16^{\circ} \mathrm{C}$ with an average of $13.1^{\circ} \mathrm{C}$. Our analyses (results not shown) suggest that temperature had little influence on the estimates of the model parameters. If a $\mathrm{Q}_{10}$ based temperature response of microzooplankton ingestion rates is assumed (Hansen et al. 1997), corrections for temperature variations can be made by multiplying $g_{\max }$ by a temperature factor. This could facilitate the study of seasonal variability in grazing rates or the application of our model to varying temperatures.

\section{Comparison of modeled and measured grazing rates}

To compare an independent set of measured grazing rates $\left(m_{\mathrm{e}}\right.$ from 2006$)$ to our model, we replace $m$ with $m_{\mathrm{e}}$ in Eq. (8) to give a form with the measured losses on the left-hand side and the modeled losses on the right:

$$
m_{\mathrm{e}}=g_{\max } \frac{f(P)}{P} Z
$$

This equation thus compares the measured specific grazing loss of phytoplankton from dilution experiments $\left(m_{\mathrm{e}}\right)$ to our predicted $m$ from the values of $P$ and $Z$ using the parameterized nonlinear grazing responses in Eqs. (8) \& (11, 12 \& 13). A comparison of the measured and modeled grazing rates (Fig. 4) shows that the models do equally well in explaining the variability in the 2006 field data $\left(\mathrm{R}^{2} \approx 0.5\right.$ for Ivlev, Holling II and Holling III). When grazing rate is low, the model results overlay each other and generally 

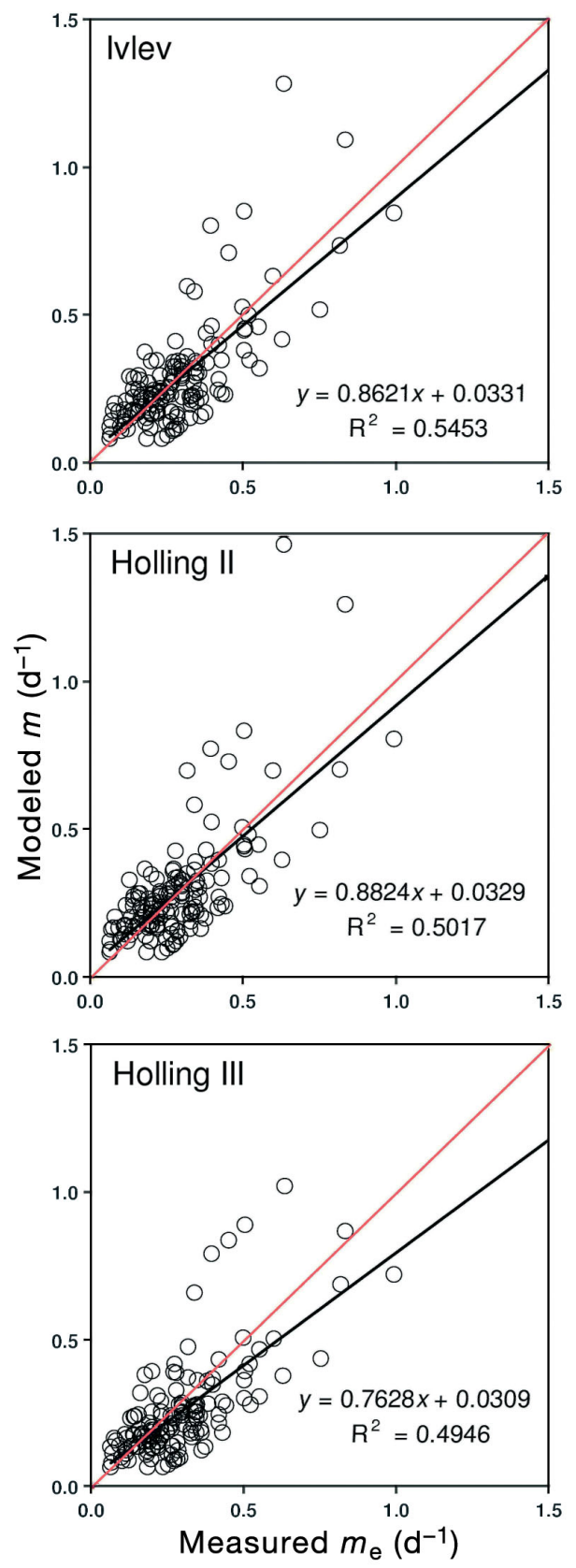

Fig. 4. Biomass grazing rates measured from California Current Ecosystem data $\left(m_{\mathrm{e} i} \mathrm{n}=117\right)$ compared to modeled biomass grazing rates $\left(m=g_{\max } f(P) Z / P\right)$ using the Ivlev, Holling II, and Holling III functions. Black lines: linear regressions; red lines: 1:1 relationships

agree well with measurements. However, they show substantial differences when grazing rates are high, which was mainly in the coastal areas. Our results also indicate that the Ivlev and Holling II models (slopes of 0.86 and 0.88 , respectively) agree slightly better with measured $m_{\mathrm{e}}$ than the Holling III model did (slope of 0.76). However, statistical tests compar- ing predicted grazing rates with measured grazing rates suggest that they are not significantly different $\left(\mathrm{R}^{2}>0.49, \mathrm{p}<0.0001\right)$. From these results, we conclude that all 3 functions give equally good representations of microzooplankton grazing responses for both the California coastal and offshore ecosystems. This finding also suggests that the mathematical differences among the 3 grazing formulations in response to low food concentrations are not important in their application to field data.

Vertical profiles of measured and modeled grazing rates (Fig. 5) show that all 3 of the parameterized grazing functions in Eqs. (10, 11 \& 12) give good agreement with the data, especially in reproducing the grazing rates in offshore regions. Model predictions of grazing rates in coastal regions differ among the 3 nonlinear models, although they all follow the observed vertical patterns of grazing rates. Both the Ivlev and Holling II functions overestimate grazing rates in coastal regions, particularly near the surface. The Holling II results generally agree with the Ivlev predictions in offshore regions but give slightly higher grazing rates in coastal regions, where phytoplankton biomass is elevated. The Holling III function generally predicts lower grazing rates in both coastal and offshore regions compared to the other 2 models but agrees slightly better with data from dilution experiments at high-biomass inshore stations (Fig. 5). This may be a coincidence given that there were fewer data from regions of high planktonic biomass to use for model parameterization. Our findings might be applicable in other regions of the world's ocean because we have parameterized and tested these grazing models across relatively diverse marine environments ranging from a coastal upwelling system to the oligotrophic pelagic ocean. Given the relative paucity of experimental data from nearshore areas, which are disproportionately important for regional productivity, temporal variability and response to climate perturbation, focusing additional field observations in this portion of the CCE would be useful.

\section{Patterns of microzooplankton grazing in the SCCS}

With the parameterized grazing models, we can simulate phytoplankton mortality due to microzooplankton grazing in the California Current coastal and pelagic ecosystems using measured biomasses of phytoplankton and microzooplankton. Grazing rates tend to be higher near the surface where both phytoplankton and zooplankton are more concentrated, 

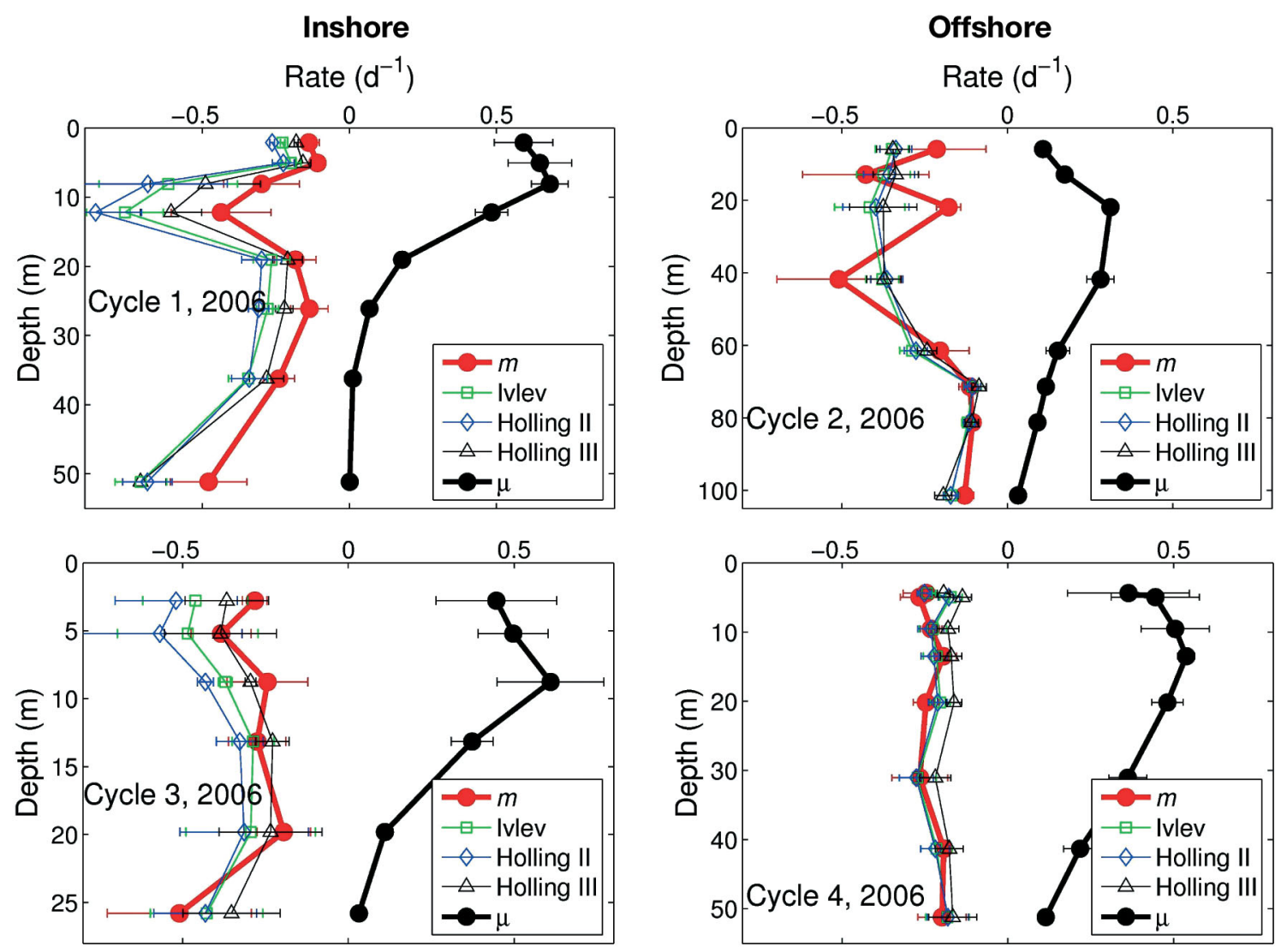

Fig. 5. Vertical patterns of microzooplankton grazing rates $\left(g_{\max } f(P) Z / P\right)$ from the Ivlev, Holling II and Holling III model predictions shown with measured grazing rates $\left(m_{\mathrm{e}}\right)$ and modeled growth rates ( $\mu$, Li et al. 2010) for the Southern California coastal and pelagic ocean. Cycles 1 and 3 were located in coastal waters, while Cycles 2, 4 and 5 were in offshore waters. Vertical profiles of (red line) $m_{\mathrm{e}}$ are derived from dilution experiments on data sets collected in 2006 that are completely independent of the (thin lines) modelpredicted grazing rates

and the rates decrease with depth. The highest rates of grazing, found in nutrient-rich coastal waters during Cycles 1 and 3, are about 2 times greater than those in offshore oligotrophic areas (Cycles 2 and 5). These variations of microzooplankton grazing impact on phytoplankton are consistent with nearshoreoffshore trends in planktonic community structure and phytoplankton primary production (Landry et al. 2009).

If we combine the Holling II model of Eq. (11) into Eq. (8), we have:

$$
m=g_{\max } \frac{Z}{C_{\mathrm{II}}+P}
$$

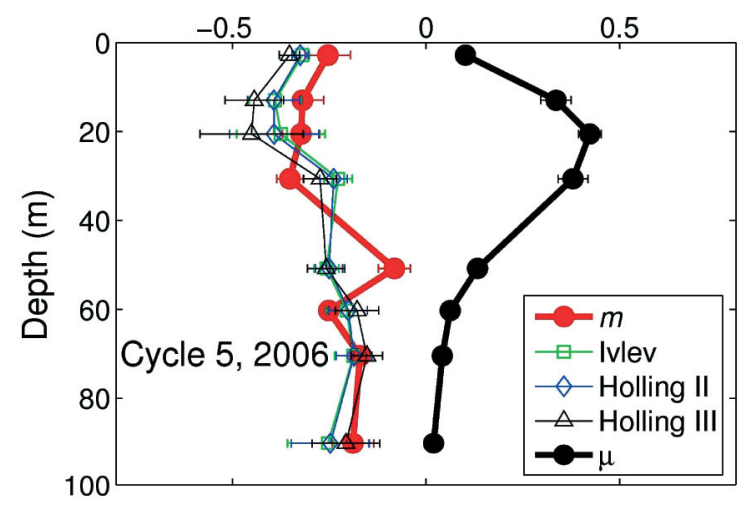

This equation gives the grazing mortality rate from dilution experiments as a function of the biomasses of both the microzooplankton grazers $(Z)$ and the phytoplankton prey $(P)$. Although the higher phytoplankton biomass near the coast is a result of enhanced nutrient supply and may favor the growth of microzooplankton there, the biomass ratios of microzooplankton to phytoplankton in the nearshore stations of Cycle $1(Z / P=0.19 \pm 0.06)$ are, on average, not much different from those at the offshore stations of Cycle $5(Z / P=0.18 \pm 0.03)$. However, the low phytoplankton biomass offshore at depths within the lower euphotic zone-biomasses lower than the 
half-saturation constant $C_{\text {II }}$ of $0.13 \mu \mathrm{M}$ (Holling II model) - leads to a much lower value of $Z /\left(K_{2}+P\right)$ and thus limits the grazing rate of microzooplankton there. In contrast to the small-cell Prochlococcus and Synechococcus-dominated system in offshore waters, the nearshore coastal region in the SCCS is dominated by large phytoplankton such as diatoms and autotrophic dinoflagellates (Landry et al. 2009). The lack of a significant depression of microzooplankton grazing in the coastal area, as might be expected if large phytoplankton enjoyed a size refuge from microzooplankton herbivory, implies that there are compensatory changes in the composition and structure of the grazer assemblage. Clearly some of the larger heterotrophic protists, such as oligotrich ciliates, tintinnids and heterotrophic dinoflagellates, which are especially common in our study area, can feed very readily, if not preferentially, on diatoms (e.g. Pierce \& Turner 1993, Hansen \& Calado 1999).

Our model also reveals a tight coupling between phytoplankton growth rates and mortality rates in the SCCS (Fig. 5). Net positive growth of phytoplankton $(\mu-m>0)$ was found at nearshore stations (Cycles 1 and 3), particularly in the surface layer where phytoplankton biomass was high. In contrast, growth and grazing were nearly balanced in the offshore regions (Cycles 2 and 5), where efficient nutrient recycling is essential for maintaining local phytoplankton primary production (Li \& Hansell 2008, Landry et al. 2009). The balance of phytoplankton growth and grazing observed in the offshore regions may explain the relatively steady-state character of the oligotrophic ocean, such as seen in data from the equatorial Pacific Ocean (Landry et al. 1995, 2011). We expect mesozooplankton to play a larger grazing role in coastal regions than in offshore regions, and that this is evident in higher ratios of mesozooplankton to microzooplankton grazing impact in SCCS coastal sites compared to those offshore (Landry et al. 2009). To better address the growth and grazing of phytoplankton across the spectrum of SCCS environmental conditions, future modeling studies need to incorporate parameterizations of mesozooplankton grazing from field data.

In the present data, a subsurface maximum in the microzooplankton grazing rate was found in both coastal and pelagic regions (Fig. 5). This can be explained by the vertical distributions of both phytoplankton and microzooplankton, as shown in Eq. (8) where the specific grazing rate is controlled by the densities of both grazer and prey. The subsurface grazing maxima were generally coincident with the subsurface maxima of phytoplankton growth rate (Landry et al. 2009, Li et al. 2010). The existence of such subsurface phytoplankton growth-rate maxima in the SCCS has been suggested to reflect physiological responses of phytoplankton to vertical gradients in ambient light, nutrients, temperature and internal community structure (Li et al. 2010). Similarly, subsurface maxima in grazing mortality may be interpreted as an aggregate response of microzooplankton grazers to the availability and quality of their prey. The specific growth rate of microzooplankton can be expressed as:

$$
\mu_{\text {zoo }}=g_{\max } f(P) \gamma=m\left(\frac{P}{Z}\right) \gamma
$$

where $\mu_{\text {zoo }}$ is the microzooplankton specific growth rate, $\gamma$ is the microzooplankton gross growth efficiency, and $g_{\max } f(P)$ is the microzooplankton-specific grazing rate. This equation suggests that the growth rate of microzooplankton should be approximately proportional to the grazing rate on phytoplankton $(m)$ if $\gamma$ and $P / Z$ are relatively constant. Thus, subsurface maxima of microzooplankton growth rates should occur at the grazing maxima. The tight coupling between phytoplankton growth and microzooplankton grazing in vertical profiles indicates that microzooplankton grazing represents an important pathway for utilization of photosynthetically derived organic carbon throughout the range of SCCS environmental conditions. The findings here are also consistent with suggestions that microzooplankton are an important source of phytoplankton mortality in large-cell dominated coastal ecosystems as well as in the open ocean (e.g. Strom et al. 2001, Calbet \& Landry 2004).

When general bulk concentrations, such as chl a or nitrate, are used as the main constraints for tuning and testing models against field data, results can often be ambiguous. There are many alternate ways for a model to generate a given concentration. In contrast, field rate estimates, such as growth or grazing, provide much stronger constraints for testing model behaviors and performance, but they require considerably more effort to generate. Here we have demonstrated how field rate and community biomass determinations can be applied to parameterizing functions that capture the aggregate grazing response of microzooplankton to variations of phytoplankton carbon. In our particular case, the data provide rigorous constraints to parameter values that fit field observations over a broad range of environmental conditions in the southern CCE. This represents a significant and deliberate step in developing the framework for models that can reliably represent plankton dynamics of the CCE region. 
Acknowledgements. We thank the LTER-CCE team for support during our research. The funding for this work comes from US National Science Foundation grants OCE 04-17616 and 10-26607 for the CCE-LTER Program. Q.P.L. acknowledges the support from a Scripps Institution of Oceanography Postdoctoral Fellowship.

\section{LITERATURE CITED}

Calbet A, Landry MR (2004) Phytoplankton growth, microzooplankton grazing, and carbon cycling in marine systems. Limnol Oceanogr 49:51-57

Chai F, Dugdale RC, Peng TH, Wilkerson FP, Barber RT (2002) One-dimensional ecosystem model of the equatorial Pacific upwelling system. Part I: model development and silicon and nitrogen cycle. Deep-Sea Res II 49: 2713-2745

Dolan JR, Gallegos CL, Moigis A (2000) Dilution effects on microzooplankton in dilution grazing experiments. Mar Ecol Prog Ser 200:127-139

Edwards AM (2001) Adding detritus to a nutrient-phytoplankton-zooplankton model: a dynamical-systems approach. J Plankton Res 23:389-413

Eppley RW, Reid FMH, Strickland JDH (1970) Estimates of phytoplankton crop size, growth rate, and primary production. In: Strickland JDH (ed) The ecology of the plankton off La Jolla, California, in the period April through September, 1967. Bull Scripps Inst Oceanogr, Vol 17. University of California Press, Berkeley, CA, p 33-42

Fennel K, Losch M, Schröter J, Wenzel M (2001) Testing a marine ecosystem model: sensitivity analysis and parameter optimization. J Mar Syst 28:45-63

Follows MJ, Dutkiewicz S, Grant S, Chisholm SW (2007) Emergent biogeography of microbial communities in a model ocean. Science 315:1843-1846

Franks PJS, Wroblewski JS, Flierl GR (1986) Behavior of a simple plankton model with food-level acclimation by herbivores. Mar Biol 91:121-129

Frost BW (1991) The role of grazing in nutrient-rich areas of the open sea. Limnol Oceanogr 36:1616-1630

> Garrison DL, Gowing MM, Hughes MP, Campbell L and others (2000) Microbial food web structure in the Arabian Sea: a US JGOFS study. Deep-Sea Res II 47: 1387-1422

Hansen PJ, Calado AJ (1999) Phagotrophic mechanisms and prey selection in free-living dinoflagellates. J Eukaryot Microbiol 46:382-389

Hansen PJ, Bjørnsen PK, Hansen BW (1997) Zooplankton

Editorial responsibility: Edward Durbin,

Narragansett, Rhode Island, USA grazing and growth: scaling within the 2- to 2000- $\mu \mathrm{m}$ body-size range. Limnol Oceanogr 42:687-704

Holling CS (1959) Some characteristics of simple types of predation and parasitism. Can Entomol 91:385-398

Ivlev VS (1961) Experimental ecology of the feeding of fishes. (translated from Russian by D Scott). Yale University Press, New Haven, CT

Jackson GA (1980) Phytoplankton growth and zooplankton grazing in oligotrophic oceans. Nature 284:439-441

> Landry MR, Hassett RP (1982) Estimating the grazing impact of marine micro-zooplankton. Mar Biol 67: 283-288

> Landry MR, Kirshtein J, Constantinou J (1995) A refined dilution technique for measuring the community grazing impact of microzooplankton, with experimental tests in the central equatorial Pacific. Mar Ecol Prog Ser 120: 53-63

> Landry MR, Ohman MD, Goericke R, Stukel MR, Tsyrklevich K (2009) Lagrangian studies of phytoplankton growth and grazing relationships in a coastal upwelling ecosystem off Southern California. Prog Oceanogr 83: 208-216

- Landry MR, Selph KE, Taylor AG, Décima M, Balch WM, Bidigare RR (2011) Phytoplankton growth, grazing and production balances in the HNLC equatorial Pacific. Deep-Sea Res II 58:524-535

> Li QP, Hansell DA (2008) Nutrient distributions in baroclinic eddies of the oligotrophic North Atlantic and inferred impacts on biology. Deep-Sea Res II 55:1291-1299

Li QP, Franks PJS, Landry MR, Goericke R, Taylor AG (2010) Modeling phytoplankton growth rates and chlorophyll to carbon ratios in California coastal and pelagic ecosystems. J Geophys Res 115:G04003

Pierce RW, Turner JT (1993) Global biogeography of marine tintinnids. Mar Ecol Prog Ser 94:11-26

Sherr EB, Sherr BF (1993) Preservation and storage of samples for enumeration of heterotrophic protists. In: Kemp PF, Sherr BF, Sherr EB, Cole JJ (eds) Handbook of methods in aquatic microbial ecology. Lewis Publishers, Boca Raton, FL, p 207-212

Steele JH, Henderson EW (1992) The role of predation in plankton models. J Plankton Res 14:157-172

Strom SL, Brainard MA, Holmes JL, Olson MB (2001) Phytoplankton blooms are strongly impacted by microzooplankton grazing in coastal North Pacific waters. Mar Biol 138:355-368

Taylor AG, Landry MR, Selph KE, Yang EJ (2011) Biomass, size structure and depth distributions of the microbial community in the eastern equatorial Pacific. Deep-Sea Res II 58:342-357

Submitted: November 19, 2010; Accepted: July 25, 2011

Proofs received from author(s): September 30, 2011 